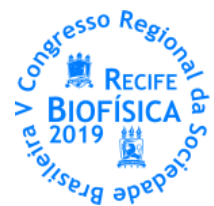

\title{
DESENVOLVIMENTO DE MODELOS ATOMÍSTICOS PARA ESCOVAS MOLECULARES
}

\author{
Breno S. Gazal ${ }^{1 *}$, Denys E. S. Santos ${ }^{1}$, Thereza A. Soares ${ }^{1}$ \\ ${ }^{1}$ Grupo de Modelagem de BioMateriais (BioMat), Dept. de Química Fundamental, Universidade Federal de Pernambuco, Brasil \\ brenosoaresg@gmail.com
}

\begin{abstract}
INTRODUÇÃO
Escovas ou polímeros moleculares são formados por densos arranjos de cadeias poliméricas fixadas em uma superfície através de uma das extremidades. 0 denso empacotamento das cadeias poliméricas resulta em repulsão eletrostática e impedimento estérico entre cadeias vizinhas, fazendo com que as mesmas adotem uma conformação distendida quando em solvente compatível. (BARBEY et al., 2009; KRISHNAMOORTHY et al., 2014). A ligação covalente entre as cadeias poliméricas e grupos funcionais na superfície de substrato resulta em uma perda de entropia dos polímeros constituintes de escovas moleculares comparativamente ao mesmo polímero livre em solução. Por esta razão, escovas moleculares exibem propriedades muito distintas daquelas exibidas pelos mesmos polímeros livres em solução. As propriedades físicoquímicas inerentes às escovas moleculares permitem numerosas aplicações em biomedicina, inclusive como revestimentos antiincrustantes contra proteínas e bactérias e carreamento controlado de ácidos nucléicos para terapia gênica. (RODRIGUEZ-EMMENEGGER et al, 2012; GAO et al, 2011; KRISHNAMOORTHY et al, 2017; Ll et al, 2018).

No entanto, uma compreensão molecular das interações entre escovas moleculares e biomoléculas permanece incompleta, dificultando o planejamento e síntese de novas escovas com propriedades desejáveis para uma determinada aplicação biomédica. Modelos moleculares atomísticos que capturem adequadamente as propriedades físico-químicas de diferentes escovas moleculares, possibilitando a representação de diferentes solventes, soluções salinas e estados de protonação das cadeias poliméricas são necessários para elucidar o comportamento de associação/dissociação de biomoléculas em escovas moleculares.

O objetivo deste trabalho é o desenvolvimento e teste de modelos moleculares para escovas moleculares com propriedades antiadesivas para proteínas do soro sanguíneo.
\end{abstract}

\section{MATERIAIS E MÉTODOS}

No presente trabalho foram construídas topologias moleculares e assinalados parâmetros atômicos para dois tipos de compostos constituintes de escovas moleculares, a saber o 2-hidroxietil metacrilato (HEMA) e carboxibetaina metacrilato (CBMA-2) (Figura 1). Para isto, foram utilizados parâmetros atômicos adequadamente validados para a reprodução do comportamento de hidratação de polímeros constituintes das escovas moleculares 2(dimethylamino)ethyl methacrylate (DMAEMA) e (trimethylamino) ethyl methacrylate chloride (METAC). (SANTOS et al, 2019). 0 campo de força GROMOS 54A7 foi utilizado para descrever os parâmetros atômicos. (SCHMID et al., 2011) A topologia dos grupos iniciadores, cadeias alifáticas dos polímeros assim como definição dos tipos de átomos e potenciais de interação de van der Waals foram extraídos do trabalho de Santos et al. (2019). Os parâmetros para os termos da função de energia potencial ligados e não-ligados são apresentados na Tabela 1.<smiles>CCC(C)(CC)C(=O)OCCO</smiles>

A
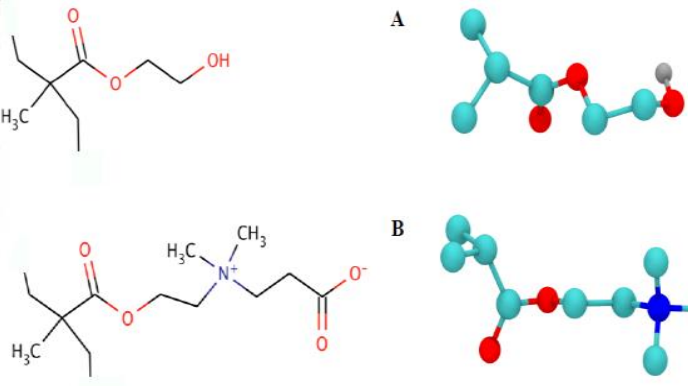

B

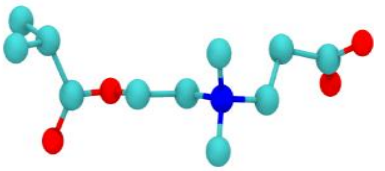

C
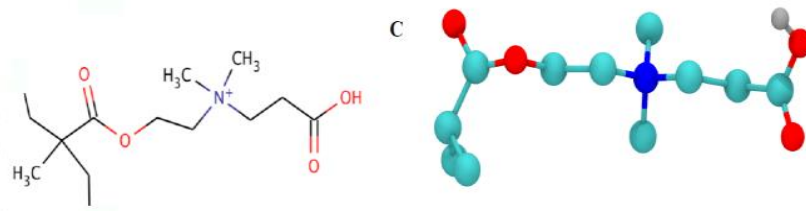

Figura 1. Estrutura química e molecular dos polímeros modelados neste trabalho. A) 2hydroxyethyl methacrylate (HEMA), B) carboxybetaine methacrylate (CBMA-2) deprotonado e C) carboxybetaine methacrylate (CBMA-2) protonado (fonte: autor)

\section{RESULTADOS E DISCUSSÃO}

Recentemente, o nosso grupo desenvolveu um conjunto de parâmetros atomísticos para escovas moleculares formadas por dimetil(amino etil metacrilato) (DMAEMA) e 2-metacriloiloxietila trimetila amonia cloride (PMETAC) compatíveis com o campo de força GROMOS. (SANTOS et al, 2019) 0 protocolo de parametrização permite o desenvolvimento modular de novas topologias e parâmetros de modo que apenas novos grupos funcionais precisam ser parametrizados. Além disso, o protocolo garante a compatibilidade e universalidade dos novos parâmetros atômicos com os demais parâmetros já desenvolvidos para escovas moleculares e vários tipos de solventes e sais disponíveis no campo de força GROMOS.

Neste trabalho, o protocolo de parametrização foi aplicado à criação de novas topologias e desenvolvimento de parâmetros atômicos para escovas moleculares resistentes à adesão proteica. Após o assinalamento de parâmetros atômicos para os diferentes monômeros, estes foram simulados em solvente explícito. Estas simulações serviram de teste para monitorar a qualidade dos parâmetros atômicos na reprodução da geometria de cada monômero. Os parâmetros atômicos são apresentados na Tabela 1. Foi constatado que todos os modelos moleculares mantiveram a geometria molecular esperada, e o padrão de interações intermoleculares entre os diferentes grupos funcionais dos respectivos monômeros e o solvente aquoso foi caracterizado. Presentemente, simulações de dinâmica molecular de escovas 
moleculares compostas por repetições destes monômeros estão sendo realizadas para investigar como o padrão de hidratação das escovas é afetado pela densidade de cadeias poliméricas.

Tabela 1: Parâmetros atômicos utilizados na construção das estruturas dos polímeros.

\begin{tabular}{|c|c|c|}
\hline Grupo funcional & Tipos de átomos & Carga atômica \\
\hline Cadeia alifática & $\mathrm{CH}_{0}, \mathrm{CH}_{2}$ or $\mathrm{CH}_{3}$ & 0.000 \\
\hline \multirow{4}{*}{ Éster } & C & 0.580 \\
\hline & $\mathrm{CH}_{2}$ & 0.160 \\
\hline & 0 & -0.380 \\
\hline & $\mathrm{OE}$ & -0.360 \\
\hline \multirow{2}{*}{ Trimetil amônio } & $\mathrm{CH}_{2}$ or $\mathrm{CH}_{3}$ & 0.250 \\
\hline & $\mathrm{NL}$ & 0.000 \\
\hline Ligações & $k_{b}\left[10^{6} \mathrm{~kJ} \cdot \mathrm{mol}^{-1} \cdot \mathrm{nm}^{-4}\right]^{\mathrm{a}}$ & $b_{o}[\mathrm{~nm}]$ \\
\hline
\end{tabular}

$\mathrm{CH}_{n}-\mathrm{CH}_{n}$ or $\mathrm{CH}_{n}-\mathrm{C}$

7.15

0.153

\begin{tabular}{|c|c|c|c|}
\hline $\mathrm{C}-\mathrm{O}$ & 16.60 & 0.123 & \\
\hline$C-O E$ & 10.20 & 0.136 & \\
\hline $\mathrm{CH}_{2}-\mathrm{OE}$ & 8.18 & 0.143 & \\
\hline $\mathrm{CH}_{n}-\mathrm{N}$ & 8.71 & 0.147 & \\
\hline Ângulos & $k_{\mathrm{D}}\left[\mathrm{kJ} . \mathrm{mol}^{-1}\right]^{\mathrm{b}}$ & $\square_{o}[\mathrm{deg}]$ & \\
\hline $\mathrm{CH}_{\mathrm{n}}-\mathrm{CH}_{\mathrm{n}}-\mathrm{CH}_{\mathrm{n}}$ & 520.00 & 109.50 & \\
\hline $\mathrm{CH}_{n}-\mathrm{NL}-\mathrm{CH}_{n}$ & 520.00 & 109.50 & \\
\hline $\mathrm{CH}_{\mathrm{n}}-\mathrm{NT}-\mathrm{CH}_{\mathrm{n}}$ & 545.00 & 113.00 & \\
\hline $\mathrm{CH}_{0}-\mathrm{C}-\mathrm{O}$ & 750.00 & 125.00 & \\
\hline $\mathrm{CH}_{0}-\mathrm{C}-\mathrm{OE}$ & 545.00 & 113.00 & \\
\hline $\mathrm{O}-\mathrm{C}-\mathrm{OE}$ & 700.00 & 122.00 & \\
\hline $\mathrm{C}-\mathrm{OE}-\mathrm{CH}_{2}$ & 620.00 & 116.00 & \\
\hline $\mathrm{OE}-\mathrm{CH}_{2}-\mathrm{CH}_{2}$ & 530.00 & 111.00 & \\
\hline $\mathrm{CH}_{2}-\mathrm{CH}_{2}-\mathrm{NL}, \mathrm{NT}$ & 610.00 & 115.00 & \\
\hline Diedro impróprio & $k_{a}\left[\mathrm{~kJ} \cdot \mathrm{mol}^{-1} \cdot \mathrm{rad}^{-2}\right]$ & $\square_{o}[\mathrm{deg}]$ & \\
\hline $\mathrm{CH}_{2}-\mathrm{C}-\mathrm{CH}_{3}-\mathrm{CH}_{0}$ & 334.84 & 35.2644 & \\
\hline $\mathrm{O}-\mathrm{CH}_{0}-\mathrm{OE}-\mathrm{C}$ & 167.42 & 0.0000 & \\
\hline Diedro próprio & $k_{\square}\left[\mathrm{kJ} . \mathrm{mol}^{-1}\right]$ & 口 & $\mathrm{n}$ \\
\hline $\mathrm{CH}_{0}-\mathrm{C}-\mathrm{OE}-\mathrm{CH}_{2}$ & 33.5 & 180.0 & 2 \\
\hline $\mathrm{CH}_{2}-\mathrm{CH}_{0}-\mathrm{C}-\mathrm{O}, \mathrm{OE}$ & 2.93 & 0.0 & 3 \\
\hline $\mathrm{C}-\mathrm{OE}-\mathrm{CH}_{2}-\mathrm{CH}_{2}$ & 3.77 & 0.0 & 3 \\
\hline $\mathrm{OE}-\mathrm{CH}_{2}-\mathrm{CH}_{2}-\mathrm{NT}$ & 8.62 & 0.0 & 3 \\
\hline $\begin{array}{l}\mathrm{CH}_{2}-\mathrm{CH}_{2}-\mathrm{NT}, \mathrm{NL}-\mathrm{CH}_{3}, \\
\mathrm{H}\end{array}$ & 3.77 & 0.0 & 3 \\
\hline $\mathrm{CH}_{n}-\mathrm{CH}_{n}-\mathrm{CH}_{n}-\mathrm{CH}_{n}$ & 5.92 & 0.0 & 3 \\
\hline $\mathrm{CH}_{3}-\mathrm{CH}_{2}-\mathrm{CH}_{2}-\mathrm{OE}$ & 5.92 & 0.0 & 3 \\
\hline
\end{tabular}

\section{CONCLUSÕES}

Foram construídas e simulados modelos moleculares para os compostos a saber o 2-hidroxietil metacrilato (HEMA) e carboxibetaina metacrilato (CBMA-2) considerando diferentes valores de $\mathrm{pH}$ representados através de diferentes estados de protonação de grupos ionizáveis. As simulações de dinâmica molecular atomística mostram que os monômeros mantem a geometria estrutural e interações intermoleculares desejadas e indicam que simulações de escovas moleculares contendo da ordem de 1000 monômeros podem ser iniciadas a partir destes parâmetros atômicos.

\section{REFERÊNCIAS}

BARBEY, R.; LAVANANT, L.; PARIPOVIC, D.; SCHUWER, N.; SUGANAUX, C.; TUGULU, S.; KLOK, H. A. Polymer Brushes via Surface-Initiated Controlled Radical Polymerization: Synthesis, Characterization, Properties, and Applications. Chemical Reviews, v. 109(11), p. 5437-5527, 2009.

GAO, G.; YU, K.; KINDRACHUK, J.; BROOKS, D. E.; HANCOCK, R. E.; KIZHAKKEDATHU, J. N. Antibacterial Surfaces Based on Polymer Brushes: Investigation on the Influence of Brush Properties on Antimicrobial Peptide Immobilization and Antimicrobial Activity . Biomacromolecules, v. 12, p. 3715, 2011.

KRISHNAMOORTHY, M.; HAKOBYAN, S.; RAMSTEDT, M.; GAUTROT, J. E. Surface-Initiated Polymer Brushes in the Biomedical Field: Applications in Membrane Science, Biosensing, Cell Culture,
Regenerative Medicine and Antibacterial Coatings. Chemical Reviews, v. 114(21), p. 10976-11026, 2014.

KRISHNAMOORTHY, M.; LI, D.; SHARILI, A. S.; GULIN-SARFAZ, T.; ROSENHOLM, J. M.; GAUTROT, J. E. Solution Conformation of Polymer Brushes Determines Their Interactions with DNA and Transfection Efficiency. Biomacromolecules, v. 18(12), p. 4121 4132, 2017.

LI, D.; SHARILI, A. S.; CONNELLY, J.; GAUTROT, J. E. Highly Stable RNA Capture by Dense Cationic Polymer Brushes for the Design of Cytocompatible, Serum-Stable SiRNA Delivery Vectors. Biomacromolecules, v. 19, p. 606-615, 2018.

RODRIGUEZ-EMMENEGGER, C.; HOUSKA, M.; ALLES, A. B.; BRYNDA, E. Surfaces Resistant to Fouling from BiologicalFluids: Towards Bioactive Surfaces for RealApplications. Macromolecular Bioscience, v. 12(10), p. 1413-1422, 2012.

SANTOS, D. E. S.; LI, D.; RAMSTEDT, M.; GAUTROT, J. E.; SOARES T. A. Conformational Dynamics and Responsiveness of Weak and Strong Polyelectrolyte Brushes: Atomistic Simulations of PDMAEMA and PMETAC. Langmuir, v. 207, p. 266-275, 2019.

SCHMID, N.; EICHENBERGER, A. P.; CHOUTKO, A.; RINIKER, S.; WINGER, M.; MARK, A. E.; VAN GUNSTEREN, W. F. Definition and testing of the GROMOS force-field versions $54 A 7$ and 54B7. European Biophysical Journal, v. 40(7), p. 843-856, 2011 